\title{
Comparison of native and capric acid-enriched mustard oil effects on oxidative stress and antioxidant protection in rats
}

\author{
Avery Sengupta and Mahua Ghosh* \\ Department of Chemical Technology, University College of Science E Technology, University of Calcutta, 92, A.P.C. Road, \\ Kolkata 700009, India
}

(Received 10 February 2011 - Revised 17 June 2011 - Accepted 19 June 2011 - First published online 1 November 2011)

\section{Abstract}

The present study evaluated the effect of mustard oil enriched in capric acid, a medium-chain fatty acid, on antioxidant enzyme activities in liver and brain and on the levels of malondialdehyde (MDA) in liver, brain and plasma in rats; the effect of adding cholesterol to the diet was also investigated. Charles Foster male albino rats weighing 80-100 g were fed one of four diets for $30 \mathrm{~d}$ (six rats per group). In the absence of added dietary cholesterol, the addition of capric acid to the diet resulted in lower plasma total cholesterol, non-HDL-cholesterol and TAG concentrations, higher HDL-cholesterol concentrations, higher antioxidant enzyme activities in liver and brain and lower MDA concentrations in liver, brain and plasma. Adding cholesterol to the diet increased plasma total cholesterol, non-HDL-cholesterol and TAG concentrations, decreased HDL-cholesterol concentration, decreased the activities of antioxidant enzymes and increased tissue and plasma MDA concentrations. Including capric acid in the diet of rats receiving cholesterol at least partly prevented the effects of the increased cholesterol. It is concluded that compared with native mustard oil, capric acid-enriched mustard oil improves blood lipids, enhances antioxidant protection and reduces lipid peroxidation.

Key words: Antioxidant enzymes: Capric acid: Mustard oil: Plasma lipids: Lipid peroxidation

Observational studies have shown that a high intake (more than $15 \%$ of daily energy intake) of SFA is associated with high blood concentrations of cholesterol and high CHD mortality $^{(1,2)}$. However, a recent meta-analysis of prospective epidemiological studies suggested that there is no significant evidence for concluding that dietary saturated fat is associated with an increased risk of CHD or $\mathrm{CVD}^{(3)}$. In addition, there is good evidence that not all dietary SFA are necessarily associated with a negative impact on atherosclerosis biomarkers and that their specific identity, individual intake level and dietary origin must be considered ${ }^{(4-7)}$. For instance, mediumchain SFA (MCFA) have been shown not to increase blood cholesterol concentrations in human subjects ${ }^{(8)}$. Furthermore, TAG composed of MCFA (Medium-chain TAG) can be used as a readily available energy source for quick energy, which may lead to a decrease in glucose requirements. Also, because MCFA are not incorporated into chylomicrons, they are less likely to be stored in adipose tissues. Therefore, structured lipids containing both essential fatty acids and MCFA may be useful to target specific diseases and metabolic conditions ${ }^{(9)}$.

Reactive oxygen species (ROS) can cause cell and tissue damage and lipid peroxidation, leading to impaired cellular function and alterations in the physico-chemical properties of cell membranes, which in turn disrupt vital functions ${ }^{(10)}$.
MCFA are likely to be highly resistant to peroxidation ${ }^{(11,12)}$. Antioxidant enzymes provide protection against ROS and, similar to many other biochemical systems, their effectiveness varies with the stage of development and other physiological aspects of the organism ${ }^{(13,14)}$. The most important antioxidant enzymes are superoxide dismutase, catalase and glutathione peroxidase $^{(13)}$. Thus, the extent of lipid peroxidation is likely to depend in part on both the activity of antioxidant enzymes and the mix of fatty acids present in a target for peroxidation ${ }^{(15)}$.

In a previous study ${ }^{(16)}$, we observed that the ingestion of MCFA along with essential fatty acids improves platelet aggregation and haematological parameters of hypercholesterolaemic rats. In the present study, we investigate the effect of capric acid (10:0), a MCFA, added to mustard oil on plasma lipids, antioxidant enzymes and lipid peroxidation in normal and hypercholesterolaemic rats.

\section{Materials and methods}

\section{Chemicals and enzymes}

Mustard oil was extracted from brown mustard seeds by the solvent extraction method and physically refined and bleached. Capric acid was procured from Sigma Chemical Company, St Louis, MO, USA. Lipase TLIM (Thermomyces

Abbreviations: GSH, reduced glutathione; MCFA, medium-chain SFA; MDA, malondialdehyde; ROS, reactive oxygen species.

*Corresponding author: Dr M. Ghosh, fax +91 33 23519755, email mahuag@gmail.com, mgchemtech@caluniv.ac.in 
Table 1. Fatty acid compositions of native and capric acid-enriched mustard oils

\begin{tabular}{|c|c|c|c|c|c|c|c|c|c|c|c|}
\hline & \multicolumn{11}{|c|}{ Fatty acid $(\%, w / w)$} \\
\hline & $10: 0$ & $16: 0$ & $18: 0$ & $18: 1 n-9$ & $18: 2 n-6$ & $18: 3 n-3$ & $20: 0$ & $20: 1 n-9$ & $22: 0$ & $22: 1 n-9$ & $24: 0$ \\
\hline Native mustard oil & 0 & $2 \cdot 2$ & $1 \cdot 2$ & $9 \cdot 4$ & $17 \cdot 9$ & $10 \cdot 8$ & 0.8 & $5 \cdot 2$ & $2 \cdot 0$ & $48 \cdot 6$ & 1.3 \\
\hline Capric acid-enriched mustard oil & 19.9 & $1 \cdot 8$ & 1.0 & $11 \cdot 1$ & $10 \cdot 6$ & $7 \cdot 2$ & 0.6 & 3.6 & 1.9 & $40 \cdot 4$ & $2 \cdot 1$ \\
\hline
\end{tabular}

lanuginosus) was a gift from Novozymes India Private Limited, Bangalore, Karnataka, India. All other reagents used were of analytical grade and procured from Merck India Limited, Mumbai, India.

\section{Preparation of experimental oil}

Capric acid-enriched mustard oil was prepared by the reaction between capric acid and mustard oil in a packed bed bioreactor using lipase TLIM as a catalyst ${ }^{(17)}$. Unreacted fatty acid was separated from the oil by vacuum distillation.

\section{Chromatographic analysis of oils}

Fatty acid compositions of native and capric acid-enriched mustard oil were analysed by GC. The oils were saponified with $0.5 \mathrm{M}-\mathrm{KOH}$ and methylated with boron trifluoride in methanol. The gas chromatograph (Agilent 6890 N; J\&W Scientific, Wilmington, DE, USA) was fitted with a DB-Wax capillary column $(30 \mathrm{~m} \times 0.32 \mathrm{~mm} \times 0.25 \mu \mathrm{m})$ and a flame ionisation detector. $\mathrm{N}_{2}, \mathrm{H}_{2}$ and airflow rate were maintained at 1, 30 and $300 \mathrm{ml} / \mathrm{min}$, respectively. Inlet and detector temperatures were kept at $250^{\circ} \mathrm{C}$ and the oven temperature was programmed to increase from 150 to $190^{\circ} \mathrm{C}$ at a rate of $15^{\circ} \mathrm{C} / \mathrm{min}$, then to hold for $5 \mathrm{~min}$, and then to increase to $230^{\circ} \mathrm{C}$ at a rate of $4^{\circ} \mathrm{C} / \mathrm{min}$, and then again to hold for $10 \mathrm{~min}$. The fatty acid compositions of the native and capric acid-enriched mustard oils are shown in Table 1 . The capric acid-enriched oil contained $19.9 \%$ of fatty acids as capric acid.

\section{Feeding experiment}

The work was done under the supervision of the Animal Ethical Committee of the Department of Chemical Technology (University of Calcutta). Charles Foster male albino rats were housed in individual cages. The rats were acclimatised for 2 weeks while receiving free access to water and to a standard laboratory diet. For the duration of the study, the rats were exposed to a $12 \mathrm{~h}$ light $-12 \mathrm{~h}$ dark cycle. Rats weighed $80-100 \mathrm{~g}$ at the start of the feeding experiment. They were divided into four groups, each consisting of six animals. Each group was fed a different diet. Diets contained native mustard oil (200 g/kg diet), native mustard oil $(200 \mathrm{~g} / \mathrm{kg}$ diet) plus cholesterol $(10 \mathrm{~g} / \mathrm{kg}$ diet $)$, capric acid-enriched mustard oil ( $200 \mathrm{~g} / \mathrm{kg}$ diet) or capric acid-enriched mustard oil $(200 \mathrm{~g} / \mathrm{kg}$ diet $)$ plus cholesterol $(10 \mathrm{~g} / \mathrm{kg}$ diet $)$. The diets were prepared weekly and stored at $-20^{\circ} \mathrm{C}$. The dietary composition is shown in Table 2 .

\section{Sample collection}

After $30 \mathrm{~d}$ of the dietary treatments, rats were fasted for $12 \mathrm{~h}$. Then they were anaesthetised with chloroform and killed. Blood samples were collected from the abdominal aorta into EDTA tubes and centrifuged at $1500 \mathrm{rpm}$ for $15 \mathrm{~min}$ to separate the erythrocytes and plasma. Liver and brain were harvested, weighed and stored at $-20^{\circ} \mathrm{C}$ until further analysis.

\section{Analysis of plasma lipid concentrations}

Total cholesterol, HDL-cholesterol and TAG concentrations were determined using enzyme kits supplied by Merck India Limited.

\section{Enzyme assays}

Measured amounts of liver and brain were homogenised in phosphate buffer. The samples were then centrifuged and the supernatants were used for the enzyme assay. The activity of catalase was determined spectrometrically by the method of Aebi ${ }^{(18)}$. Superoxide dismutase activity was assayed by measuring the auto-oxidation of haematoxylin as described by Martin et al. ${ }^{(19)}$. Reduced glutathione (GSH) was determined by the method of Ellman ${ }^{(20)}$. Total activity of glutathione peroxidase (EC.1.11.1.9.) was determined in the tissue homogenates and plasma according to Flohe \& Günzler ${ }^{(21)}$. All enzyme activities are expressed as enzyme units per mg protein. Protein content was determined using the method of Lowry et al. ${ }^{(22)}$.

\section{Products of lipid peroxidation}

For lipid peroxide measurement, approximately $1 \mathrm{~g}$ of liver or $0.4 \mathrm{ml}$ of plasma was placed into a glass centrifuge tube

Table 2. Proximate composition of the diets

\begin{tabular}{|c|c|c|c|c|}
\hline & \multicolumn{4}{|c|}{ Diet (g/kg diet) } \\
\hline & $\begin{array}{l}\text { Control } \\
\text { diet }\end{array}$ & $\begin{array}{c}\text { Control } \\
\text { diet with } \\
\text { cholesterol }\end{array}$ & $\begin{array}{l}\text { Capric } \\
\text { acid-rich } \\
\text { diet }\end{array}$ & $\begin{array}{c}\text { Capric } \\
\text { acid-rich } \\
\text { diet with } \\
\text { cholesterol }\end{array}$ \\
\hline Starch & 550 & 550 & 550 & 550 \\
\hline Fat-free casein & 180 & 180 & 180 & 180 \\
\hline Salt mixture & 40 & 40 & 40 & 40 \\
\hline Husk & 30 & 30 & 30 & 30 \\
\hline Native mustard oil & 200 & 200 & - & - \\
\hline $\begin{array}{l}\text { Capric acid-enriched } \\
\text { mustard oil }\end{array}$ & - & - & 200 & 200 \\
\hline Cholesterol & - & 10 & - & 10 \\
\hline Vitamin B capsules* & 10 & 10 & 10 & 10 \\
\hline
\end{tabular}

* Number of capsules used per kg diet. 
Table 3. Plasma lipid concentrations in rats fed the different diets (Mean values with their standard errors for six rats per diet group)

\begin{tabular}{|c|c|c|c|c|c|c|c|c|}
\hline \multirow[b]{3}{*}{ Parameters } & \multicolumn{4}{|c|}{ Native mustard oil } & \multicolumn{4}{|c|}{ Capric acid-enriched mustard oil } \\
\hline & \multicolumn{2}{|c|}{$\begin{array}{l}\text { No added } \\
\text { cholesterol }\end{array}$} & \multicolumn{2}{|c|}{ +Cholesterol } & \multicolumn{2}{|c|}{$\begin{array}{l}\text { No added } \\
\text { cholesterol }\end{array}$} & \multicolumn{2}{|c|}{+ Cholesterol } \\
\hline & Mean & SEM & Mean & SEM & Mean & SEM & Mean & SEM \\
\hline Total cholesterol (mg/l) & $772 \cdot 0^{\mathrm{a}}$ & $27 \cdot 0$ & $932 \cdot 8^{\mathrm{b}}$ & $29 \cdot 8$ & $708 \cdot 2^{\mathrm{c}}$ & $2 \cdot 3$ & $767 \cdot 1^{\mathrm{a}}$ & $18 \cdot 9$ \\
\hline HDL-cholesterol (mg/l) & $230 \cdot 0^{\mathrm{a}}$ & $22 \cdot 1$ & $169 \cdot 2^{b}$ & $21 \cdot 1$ & $306 \cdot 2^{\mathrm{c}}$ & $18 \cdot 2$ & $240 \cdot 0^{a}$ & $18 \cdot 5$ \\
\hline Non-HDL-cholesterol (mg/l) & $291 \cdot 6^{\mathrm{a}}$ & $12 \cdot 3$ & $484 \cdot 1^{\mathrm{b}}$ & 1.6 & $154.7^{\mathrm{C}}$ & $15 \cdot 6$ & $275 \cdot 4^{\mathrm{a}}$ & 9.9 \\
\hline TAG (mg/l) & $1251 \cdot 6^{\mathrm{a}}$ & $2 \cdot 2$ & $1397 \cdot 7^{\mathrm{b}}$ & $12 \cdot 9$ & $1236 \cdot 4^{\mathrm{C}}$ & 3.4 & $1328.8^{\mathrm{d}}$ & 1.0 \\
\hline
\end{tabular}

$(70 \mathrm{ml})$ for $2 \mathrm{~min}$ in a solvent mixture consisting of $10 \mathrm{ml}$ chloroform and $20 \mathrm{ml}$ methanol, and homogenised on ice. Then, $10 \mathrm{ml}$ of chloroform was added and homogenisation continued for another $30 \mathrm{~s}$. Finally, $10 \mathrm{ml}$ of redistilled water were added and the mixture was homogenised for $30 \mathrm{~s}$. The tubes were then centrifuged for $20 \mathrm{~min}$ at $4000 \mathrm{rpm}$, and the chloroform layer was separated ${ }^{(23)}$. Thiobarbituric acidreactive substances were measured according to the method described by Schmedes \& Hølmer ${ }^{(24)}$. Malondialdehyde (MDA) concentration was calculated by taking the extinction coefficient of MDA to be $1.56 \times 10^{5} / \mathrm{M} \mathrm{cm}^{(25)}$.

\section{Statistical analysis}

All the data are presented as means with their standard errors. Statistical comparisons between groups were performed using Student's $t$ test.

\section{Results}

\section{Effect of the different diets on plasma lipid concentrations}

In the absence of added dietary cholesterol, plasma total cholesterol, non-HDL-cholesterol and TAG concentrations were lower in rats fed the capric acid-enriched mustard oil compared with those fed the native mustard oil (Table 3). Conversely, HDL-cholesterol concentration was higher in rats fed the capric acid-enriched mustard oil (Table 3). Adding cholesterol to the diet increased plasma total cholesterol, non-HDL-cholesterol and TAG concentrations and decreased HDL-cholesterol concentration (Table 3). However, the plasma lipid profile was better when rats received the capric acid-enriched mustard oil plus cholesterol compared with those that received the native mustard oil plus cholesterol (Table 3).

\section{Antioxidant enzyme activities}

The same pattern of effect of the diets was seen on antioxidant enzyme activities in both liver and brain (Tables 4 and 5). In the absence of added dietary cholesterol, antioxidant enzyme activities were much higher in the liver and brain of rats fed the capric acid-enriched mustard oil compared with those fed the native mustard oil (Tables 4 and 5). Adding cholesterol to the diet decreased the activities of all enzymes, although the effect was not significant in all cases. However, all enzyme activities were higher in liver and brain when rats received the capric acid-enriched mustard oil plus cholesterol compared with those that received the native mustard oil plus cholesterol (Tables 4 and 5). The highest enzyme activities were always seen in the group receiving the capric acid-enriched mustard oil. Interestingly, enzyme activities were often higher in tissues of rats fed the capric acid-enriched mustard oil plus cholesterol than in those fed the native mustard oil.

\section{Lipid peroxidation}

The same pattern of effect of the diets was seen on MDA concentrations in liver, brain and plasma (Table 6). In the absence of added dietary cholesterol, MDA concentrations were much lower in tissues and plasma of rats fed the capric acidenriched mustard oil compared with those fed the native mustard oil (Table 6). Adding cholesterol to the diet increased

Table 4. Antioxidant activity of liver tissue

(Mean values with their standard errors for six rats per diet group)

\begin{tabular}{|c|c|c|c|c|c|c|c|c|}
\hline \multirow[b]{3}{*}{ Antioxidant enzymes } & \multicolumn{4}{|c|}{ Native mustard oil } & \multicolumn{4}{|c|}{ Capric acid-enriched mustard oil } \\
\hline & \multicolumn{2}{|c|}{$\begin{array}{l}\text { No added } \\
\text { cholesterol }\end{array}$} & \multicolumn{2}{|c|}{+ Cholesterol } & \multicolumn{2}{|c|}{$\begin{array}{l}\text { No added } \\
\text { cholesterol }\end{array}$} & \multicolumn{2}{|c|}{+ Cholesterol } \\
\hline & Mean & SEM & Mean & SEM & Mean & SEM & Mean & SEM \\
\hline CAT (U/min per mg protein) & $3 \cdot 11^{a}$ & 0.08 & $1 \cdot 7^{\mathrm{b}}$ & 0.08 & $7 \cdot 7^{\mathrm{c}}$ & 0.21 & $4 \cdot 16^{d}$ & 0.25 \\
\hline SOD (U/min per mg protein) & $1 \cdot 1^{\mathrm{a}}$ & 0.03 & $0.9^{\mathrm{b}}$ & 0.04 & $3 \cdot 12^{\mathrm{c}}$ & 0.22 & $2 \cdot 13^{d}$ & 0.22 \\
\hline GSH (U/min per mg protein) & $22 \cdot 68^{a}$ & 0.09 & $11 \cdot 89^{\mathrm{b}}$ & 0.12 & $38 \cdot 76^{c}$ & 0.08 & $25 \cdot 22^{d}$ & 0.18 \\
\hline GPx (U/min per mg protein) & $0.59^{\mathrm{a}}$ & 0.09 & $0.44^{\mathrm{b}}$ & 0.02 & $0.92^{c}$ & 0.09 & $0.75^{d}$ & 0.06 \\
\hline
\end{tabular}

CAT, catalase; SOD, superoxide dismutase; GSH, reduced glutathione; GPx, glutathione peroxidase. $\mathrm{a}, \mathrm{b}, \mathrm{c}, \mathrm{d}$ Mean values within a row with unlike superscript letters were significantly different $(P<0.05)$. 
Table 5. Antioxidant activity of brain tissue

(Mean values with their standard errors for six rats per diet group)

\begin{tabular}{|c|c|c|c|c|c|c|c|c|}
\hline \multirow[b]{3}{*}{ Antioxidant enzymes } & \multicolumn{4}{|c|}{ Native mustard oil } & \multicolumn{4}{|c|}{ Capric acid-enriched mustard oil } \\
\hline & \multicolumn{2}{|c|}{$\begin{array}{l}\text { No added } \\
\text { cholesterol }\end{array}$} & \multicolumn{2}{|c|}{+ Cholesterol } & \multicolumn{2}{|c|}{$\begin{array}{l}\text { No added } \\
\text { cholesterol }\end{array}$} & \multicolumn{2}{|c|}{+ Cholesterol } \\
\hline & Mean & SEM & Mean & SEM & Mean & SEM & Mean & SEM \\
\hline CAT (U/min per mg protein) & $2 \cdot 07^{\mathrm{a}}$ & 0.08 & $1 \cdot 24^{\mathrm{b}}$ & 0.71 & $7 \cdot 05^{\mathrm{c}}$ & 0.71 & $3.96^{\mathrm{d}}$ & 0.34 \\
\hline SOD (U/min per mg protein) & $1 \cdot 29^{\mathrm{a}}$ & 0.01 & $0.75^{\mathrm{b}}$ & 0.02 & $3.37^{\mathrm{C}}$ & 0.35 & $2 \cdot 10^{d}$ & 0.16 \\
\hline GSH (U/min per mg protein) & $22 \cdot 96^{\mathrm{a}}$ & $0 \cdot 12$ & $11 \cdot 33^{\mathrm{b}}$ & 0.89 & $37 \cdot 89^{c}$ & 0.91 & $25 \cdot 09^{d}$ & 0.23 \\
\hline GPx (U/min per mg protein) & $0.50^{\mathrm{a}}$ & 0.08 & $0.38^{\mathrm{b}}$ & 0.12 & $0 \cdot 82^{\mathrm{c}}$ & 0.13 & $0.62^{d}$ & 0.09 \\
\hline
\end{tabular}

MDA concentrations. However, MDA concentrations were lower when rats received the capric acid-enriched mustard oil plus cholesterol compared with those that received the native mustard oil plus cholesterol (Table 6). The highest MDA concentrations were always seen in the group receiving the native mustard oil plus cholesterol.

\section{Discussion}

The capric acid-enriched mustard oil comprised almost 20\% of fatty acids as capric acid. The increased capric acid content was accommodated by a reduction in the content of several other fatty acids including linoleic, $\alpha$-linolenic and erucic acids. Thus, the modified oil had a lower content of unsaturated fatty acids and PUFA.

Feeding rats a diet containing cholesterol resulted in the anticipated adverse profile of blood lipids. In human subjects, this adverse profile increases the risk of $\mathrm{CHD}^{(26-29)}$. The present study indicated that oil enriched with capric acid resulted in an improvement in the blood lipid profile even when cholesterol was present in the diet. Thus, capric acid may be useful to lower disease risk

Hypercholesterolaemia increases the levels of the lipid peroxidation product MDA in the blood and aortic tissue ${ }^{(30,31)}$. This suggests that hypercholesterolaemia induces oxidative stress. Indeed, the ROS-producing activity of polymorphonuclear leucocytes is increased in hypercholesterolaemia ${ }^{(31)}$. Various factors have been implicated in the release of ROS and polymorphonuclear leucocytes during hypercholesterolaemia ${ }^{(32)}$. ROS exert their cytotoxic effects by causing peroxidation of unsaturated fatty acids of membrane phospholipids, which can result in an elevation in membrane fluidity and permeability and loss of cellular integrity ${ }^{(33,34)}$. Here, we show that the inclusion of capric acid in the diet decreases MDA concentration even in the presence of hypercholesterolaemia, suggesting that oxidative stress was presumably lower in animals fed that diet.

The activities of antioxidant enzymes such as superoxide dismutase, catalase and glutathione peroxidase form the first line of defence against $\operatorname{ROS}^{(35)}$, and the decrease in these activities seen in rats fed cholesterol most probably contributes to the observed oxidative stress (i.e. the increased MDA concentration). Since antioxidant enzymes play an important role in controlling lipid peroxidation ${ }^{(35)}$, an increase in the activities of these enzymes can delay the progression of atherosclerosis. In the present study, the antioxidant enzyme activities were increased when capric acid was fed even when hypercholesterolaemia was induced. Restoration of the activities of these enzymes in the liver and brain tissue with capric acid may be due to the increased intracellular concentration of the non-enzymatic antioxidant GSH, whose level was decreased in the liver and brain of rats with hypercholesterolaemia. GSH was measured, expressed as $\mathrm{U} / \mathrm{min}$ per $\mathrm{mg}$ protein. Capric acid increased GSH levels in both liver and brain tissues. GSH is one of the body's most important endogenous antioxidants responsible for free radical scavenging in all cell types ${ }^{(36,37)}$. Thus, capric acid treatment offers increased antioxidant protection to hepatic tissue even during hypercholesterolaemia.

We interpret the present findings to demonstrate that capric acid is responsible for improved blood lipid profile, enhanced antioxidant defences and decreased lipid peroxidation.

Table 6. Lipid peroxidation of liver and brain homogenates and plasma peroxidation (Mean values with their standard errors for six rats per diet group)

\begin{tabular}{|c|c|c|c|c|c|c|c|c|}
\hline \multirow[b]{3}{*}{ Peroxidation } & \multicolumn{4}{|c|}{ Native mustard oil } & \multicolumn{4}{|c|}{ Capric acid-enriched mustard oil } \\
\hline & \multicolumn{2}{|c|}{$\begin{array}{l}\text { No added } \\
\text { cholesterol }\end{array}$} & \multicolumn{2}{|c|}{+ Cholesterol } & \multicolumn{2}{|c|}{$\begin{array}{l}\text { No added } \\
\text { cholesterol }\end{array}$} & \multicolumn{2}{|c|}{+ Cholesterol } \\
\hline & Mean & SEM & Mean & SEM & Mean & SEM & Mean & SEM \\
\hline Liver lipid (nм-malondialdehyde/min per mg protein) & $2 \cdot 5^{\mathrm{a}}$ & 0.07 & $6 \cdot 64^{\mathrm{b}}$ & 0.19 & $1 \cdot 19^{c}$ & 0.17 & $3 \cdot 32^{d}$ & 0.09 \\
\hline Brain lipid (nM-malondialdehyde/min per mg protein) & $2 \cdot 73^{\mathrm{a}}$ & 0.04 & $5 \cdot 74^{\mathrm{b}}$ & 0.21 & $1.00^{\mathrm{c}}$ & 0.01 & $3.04^{d}$ & 0.11 \\
\hline Plasma (nM-malondialdehyde/min per mg protein) & $6 \cdot 67^{\mathrm{a}}$ & 0.62 & $10 \cdot 93^{\mathrm{b}}$ & 0.82 & $4 \cdot 06^{\mathrm{c}}$ & 0.12 & $7 \cdot 85^{\mathrm{d}}$ & 0.28 \\
\hline
\end{tabular}

a,b,c,d Mean values within a row with unlike superscript letters were significantly different $(P<0.05)$. 
However, it must also be recognised that the capric acid-rich oil contained less PUFA than the native oil.

On the basis of the data presented here, we propose that dietary supplementation with capric acid might benefit humans, especially leading to improved antioxidant defences in individuals with hypercholesterolaemia and thereby lowering atherosclerosis risk.

\section{Acknowledgements}

The authors thank Dr Santinath Ghosh, Department of Chemical Technology, University of Calcutta for his support. M. G. conceived the study and supervised the work; A. S. conducted the experiments. Financial support was obtained from the University of Calcutta (through UPE projects). The authors declare that they have no conflict of interest.

\section{References}

1. Keys A, Menotti A, Aravanis C, et al. (2010) The Seven Countries Study: 2,289 deaths in 15 years. Lipids 45, 975-986.

2. Kromhout D, Bloemberg B, Feskens E, et al. (2000) Saturated fat, vitamin $\mathrm{C}$ and smoking predict long-term population all-cause mortality rates in the Seven Countries Study. Int $J$ Epidemiol 29, 260-265.

3. Siri-Tarino PW, Sun Q, Hu FB, et al. (2010) Meta-analysis of prospective cohort studies evaluating the association of saturated fat with cardiovascular disease. Am J Clin Nutr 91, 535-546.

4. Rioux V \& Legrand P (2007) Saturated fatty acids: simple molecular structures with complex cellular functions. Curr Opin Clin Nutr Metab Care 10, 752-758.

5. Kris-Etherton PM, Griel AE, Psota TL, et al. (2005) Dietary stearic acid and risk of cardiovascular disease: intake, sources, digestion, and absorption. Lipids 40, 1193-1200.

6. Ravnskov U (1998) The questionable role of saturated and polyunsaturated fatty acids in cardiovascular disease. J Clin Epidemiol 51, 443-460.

7. Parodi PW (2009) Has the association between saturated fatty acids, serum cholesterol and coronary heart disease been over emphasized? Int Dairy J 19, 345-361.

8. Hu FB, Stampfer MJ, Manson JE, et al. (1999) Dietary saturated fats and their food sources in relation to the risk of coronary heart disease in women. Am J Clin Nutr 70, 1001-1008.

9. Akoh CC (1995) Structured lipids - enzymatic approach. INFORM 6, 1055-1061.

10. Drew B \& Leeuwenburgh C (2002) Aging and the role of reactive nitrogen species. Ann N Y Acad Sci 959, 66-81.

11. Bray GA, Lee M \& Bray TL (1980) Weight gain of rats fed medium-chain triglycerides is less than rats fed long-chain triglycerides. Int J Obesity 4, 27-32.

12. Bach AC \& Bababayn VK (1982) Medium-chain triglycerides: an update. Am J Clin Nutr 36, 950-961.

13. Halliwell B \& Gutteridge JMC (1999) Free Radicals in Biology and Medicine, 3rd ed. Oxford: Oxford University Press.

14. Livingstone DR, O'hara SCM, Frettsome F, et al. (2001) Contaminant-mediated pro-/anti-oxidant processes and oxidative damage in early life-stages of fish. In Environment and Animal Development. Genes, Life Histories and Plasticity, pp. 173-201 [D Atkinson and M Thorndyke, editors]. Oxford: BIOS Scientific Publishers.

15. Parihar MS \& Dubey AK (1995) Lipid peroxidation and ascorbic acid status in respiratory organs of male and female freshwater catfish Heteropneustes fossilis exposed to temperature increase. Comp Biochem Physiol 112, 309-313.

16. Sengupta A \& Ghosh M (2010) Modulation of platelet aggregation, haematological and histological parameters by structured lipids on hypercholesterolaemic rats. Lipids 45, 393-400.

17. Sengupta A, Pal M, SilRoy S, et al. (2010) Comparative study of sterol ester synthesis using Thermomyces lanuginosus lipase in stirred tank and packed bed bioreactors. J Am Oil Chem Soc 87, 1019-1025.

18. Aebi H (1984) Catalase in vitro. Methods Enzymol 105, 121-126.

19. Martin JP, Dailey M \& Sugarman E (1987) Negative and positive assays of superoxide dismutase based on haematoxylin autoxidation. Arch Biochem Biophys 255, 329-336.

20. Ellman GL (1959) Tissue sulfhydryl groups. Arch Biochem Biophys 82, 70-77.

21. Flohe L \& Günzler WA (1984) Assay of glutathione peroxidase. Methods Enzymol 105, 114-121.

22. Lowry OH, Rosebrough NJ, Farr AL, et al. (1951) Protein measurement with the Folin phenol reagent. $J$ Biol Chem 193, 265-275.

23. Bligh EH \& Dyer WJ (1959) A rapid method of total lipid extraction and purification. Can J Biochem Physiol 37, 911-917.

24. Schmedes A \& Hølmer G (1989) New thiobarbituric acid (TBA) method for determining free malondialdehyde (MDA) and hydroperoxides selectivity as a measure of lipid peroxidation. J Am Oil Chem Soc 66, 813-817.

25. Dhar P, Bhattacharyya D, Bhattacharyya DK, et al. (2006) Dietary comparison of conjugated linolenic acid $(9$ cis, 11 trans, 13 trans) and $\alpha$-tocopherol effects on blood lipids and lipid peroxidation in alloxan-induced diabetes mellitus in rats. Lipids $\mathbf{4 1}, 49-54$.

26. Kannel WB, Castelli WP, Gordon T, et al. (1971) Serum cholesterol, lipoproteins and the risk of coronary heart disease. The Framingham Study. Ann Intern Med 74, 1-12.

27. Castelli WP (1988) Cholesterol and lipids in the risk of coronary artery disease. The Framingham Heart Study. Can J Cardiol 4, 5A-10A.

28. Castelli WP, Garrison RJ, Wilson PWF, et al. (1986) Incidence of coronary artery disease and lipoprotein cholesterol levels. JAMA 256, 2835-2838.

29. Gotto AM, Gorry GA, Thompson JR, et al. (1977) Relationship between plasma and lipid concentration and coronary artery disease in 96 patients. Circulation 56, 875-883.

30. Prasad K \& Kalra J (1989) Experimental atherosclerosis and oxygen-free radicals. Angiology 40, 835-843.

31. Prasad K \& Kalra J (1993) Oxygen-free radicals and hypercholesterolemic atherosclerosis: effects of vitamin E. Am Heart J 125, 958-973.

32. Freeman BA \& Crapo JD (1982) Biology of disease. Free radicals and tissue injury. Lab Invest 47, 412-426.

33. Meerson FZ, Kagon VE \& Kozlov YP (1982) The role of lipid peroxidation in pathogenesis of ischemic damage and antioxidant protection of the heart. Basic Res Cardiol 77, 465-485.

34. Frank L \& Massaro D (1980) Oxygen toxicity. Am J Med 69 $117-125$.

35. Devi GS, Prasad MH, Saraswathi I, et al. (2000) Free radicals antioxidant enzymes and lipid peroxidation in different types of leukemias. Clin Chim Acta 293, 53-62.

36. Busse E, Zimmer G, Schnopohl B, et al. (1992) Influence of alpha-lipoic acid on intracellular glutathione in vitro and in vivo. Arzneimittelforschung 42, 829-831.

37. Arivazhagan P, Juliet P \& Panneerselvam C (2000) Effect of DL-lipoic acid on the status of lipid peroxidation and antioxidants in aged rats. Pharmacol Res 41, 299-303. 